This is a pre-print of an article is published in Studies in Theatre and Performance, 36,1, 2016, p. $52-57$

\title{
Ceci n'est pas un argument appropré (this is not a proper argument)
}

\section{By Geraldine (Gerry) Harris}

\begin{abstract}
This provocation poses questions of various sizes 'inspired' by some of the written publications that have theorised the concept of Practice as Research and drawing on lessons learnt from supervising PhD's (with and without PaR). It consists of 'musing' rather than a proper argument and makes reference to feminism. Some readers might find both of these things very irritating. Throughout the course of its musing, questions asked include: 'Is it acceptable to start a sentence with 'And' in academic writing?; 'What does and does not have the status of 'theory'? And who does and does not have the status of a theorist? and 'What is a proper argument?' No answers are provided and no conclusions drawn.
\end{abstract}

\section{Ceci n'est pas un argument appropré (this is not a proper argument)}

\author{
'And the burden of proof always rests with the 'novices', whereas the \\ legitimacy of mainstream academic research is seldom fundamentally \\ challenged'. (Borgdorff 2006, 19)
}

Invited to offer a provocation for this anniversary issue I thought I might respond to the (to be applauded) announcement of the establishment of a section in this journal dedicated to the dissemination of Practice as Research projects by offering some remarks on PaR. Since, as indicated by Rachel Hann and Victor Ladron de Guevara this topic has always produced 'fierce debates', it is a safe bet for someone looking to be provocative (Hann and Ladron de 
Guevara 2015, 5). In particular I was interested in charting a history to go alongside Angela Piccini's 'histiographic perspective' on PaR (2003) but which would explore the effects of the development of this concept on the subject area, embracing teaching as well as research. This was a ludicrously over-ambitious plan for this brief commentary, not least that it is impossible to achieve without considering some of the key structural changes that have shaped this institution in the last twenty odd years, especially the RAE/REF, and it depresses me when talking about research comes back to the REF, as if this is what it is for. (It's not, is it?)

As importantly, while I was actively engaged with PaR earlier in my career and have continued to supervise PaR PhD's, I stepped away from this area a while back. It occurred to me therefore that rather than 'provocative' any intervention I might make at this stage would be irritating, especially to the 'new generation' like Hann and Ladron de Guevara, involved so dynamically with this issue.

I realised all of this, however, only after I had invested a significant amount of time reading or re-reading some of the material published about $\mathrm{PaR}$ as a general concept, or rather writing that theorises $\mathrm{PaR}$, as opposed to writing that explores the knowledge produced by specific case studies. What follows then is not really, or only, about PaR but rather raises some questions about research in theatre and performance in general inspired by this reading and by what I have learnt, and am still learning from the PhD's I supervise (with and without PaR). I suspect it is still irritating, if only because in the words of one of the more irritated (of the many irritated) reader's reports I have received over the years, the result probably consists of 'musing' rather than a 'proper' academic argument. I have never really understood this comment but either way my approach is oblique, inconclusive, even (dare I say it) a little performative.

\section{Is it acceptable to start a sentence with 'And' in academic writing?}


The quote that heads this provocation is taken from (a formally) 'unpublished' paper by Henk Bergdorff which explores the debate about PaR across the arts. One of the things that struck me about this sentence is that it starts with 'And'. This breaks a rule I was taught at school from which only a couple of genres of writing are excepted (poetry being the most notable), and traditionally this dos not include the academic kind.

Bergdorff's paper was written to be spoken which absolves it from such rules but I notice that Hann and Ladron de Guevara start one of their sentences with 'And' $(2014,5)$ and I am currently working with a brilliant $\mathrm{PhD}$ (with $\mathrm{PaR}$ ) student ${ }^{\mathrm{i}}$ who is an established practitioner outside the academy, who does this in the written component of her research. I have not commented on this because she is, of course, as aware as I am of this rule and using it is consistent with her approach to her research, which is to not accept rules (theatrical or scholarly), or at least not without thoroughly interrogating them.

Actually, once or twice in my career I have myself started a sentence with 'And' in a 'traditional' academic publication and (a sad reflection on my institutionalisation) this has felt like a small act of rebellion. I have been thinking about slipping a sentence into a refereed article beginning with 'Because' or 'But'. But I doubt I would get it past an editor.

This all may appear rather trivial and I am tempted to increase the level of seeming frivolity by observing that while, partly due to the influence of $\mathrm{PaR}$, there is a body of writing in our field that uses a poetic register to convey the affect of performance (hence perhaps the spread of 'And'), there are very few that employ a humorous one. Yet not only does a fair amount of theatre and performance employ comedy but in doing so demonstrates that it is entirely possible to engage with serious ideas through the vehicle of humour. I will resist this digression, however, even though it is within my theme which relates to the 'breaking of rules' taking account of Borgdroff's assertion 'whereas the legitimacy of mainstream 
academic research is seldom fundamentally challenged'. I also have half an eye to Martin Welton's ironic essay on PaR (2003).

It strikes me that while many of the most widely cited theorisations of PaR underline its potential to challenge the norms and forms of mainstream academic research, actually their main focus is on establishing the legitimacy and seriousness of theatre and performance practice as knowledge and the forms its documentation and dissemination could, or should take. Unquestionably, the influence of PaR has produced notable innovations of form, including within approaches to 'traditional' scholarly writing. Nevertheless, the defensive position those championing $\mathrm{PaR}$ have been forced to take up means their focus is more on struggles for it to be either excepted from, or accepted within the procedures of the 'mainstream', rather than a fundamental challenging of them.

Indeed, these theorisations usually themselves conform to the conventions for formal academic publications. As part of this I notice that the legitimatisation of practice as knowledge is often mapped out via reference to theories drawn from other disciplines, in particular the field of philosophy, rather than say the ideas and/or work of theatre and performance practitioners, practitioner-theorists or theorist -practitioners. I have also read (or read about) writing related to specific examples of $\mathrm{PaR}$ projects that does the same.

It would be woefully hypocritical of me to object to this procedure since I frequently employ the same genre of citations in my own research and will probably continue to do so because if I don't I am not taken seriously. Yet working with PaR PhD's for me, always underscores the question:

\section{What does and does not have the status of 'theory'? And who does and does not have the status of a theorist?}

It is important that such a statement not be read as a resistance to 'theory' but as an insistence that we inquire into why that category is so reductively defined and why its 
common definitions exclude so many marginalized groups within the academy. (McDowell, 1995 cited by Stanley and Wise 2000, 261)

A few years ago I worked with another brilliant PhD student (Zoe Barltrop) who had a background in professional practice but who chose to write a 'traditional' thesis that turned out not to be so very traditional after all. It was not just that it drew on her experience of performing within the genre of (popular) performance in question (circus), or that it included passages of beautifully written 'thick description' aimed at conveying the experiential and affective impact of the shows studied. Nowadays, partly (but not entirely) due to the influence of $\mathrm{PaR}$, this is not uncommon in our field. What was more unusual was her approach to the notion of 'theory'. While she worked with ideas from what she termed 'high theory', embracing philosophy and other disciplines alongside some 'canonical' theatre and performance practitioner-theorists these were sometimes used for their 'poetic' and 'expressive qualities' rather than to support, explain or elucidate. Further, these were mixed with what she observed, in the context of the academy, might be deemed 'low' or 'illegitimate' theory, which she employed for its 'critical insights' (Barltrop 2011, 45). This latter embraced not just policy documents, reviews and books and essays not written for an academic audience and passing comments from other practitioners but short stories, novels, films, children's books, radio, television programmes films, paintings and art exhibitions. ${ }^{\text {ii }}$ What these 'low theory' works had in common was that they were all about the topic and authored by people, who where they had not engaged practically with circus had at very least mused upon it (as in contemplate, ruminate, cogitate, think) and its affect, meaning and place in the world. The result was a rigorous and sophisticated piece of work that touched on complex ethical and philosophical questions but these arose out of a primary concern to speak about and from within circus as circus. 
Again, historically this sort of methodology is not entirely unheard of in approaching the study of popular forms or other genres of practices (or practitioners) for one reason or another neglected by mainstream scholarship and/or perceived as 'illegitimate' within its terms. Nevertheless, since the first shock wave of the 'theory explosion' hit our discipline (circa late 1980s) it has become increasingly common across many (but not all) areas to discuss theatre and performance primarily through reference to what Baltrop termed 'high theory'. Significantly, the 'highest' theory tends to be produced by what Liz Stanley and Sue Wise designate as 'travelling theorists', who they suggest have come to represent somewhat 'heroic figures in contemporary intellectual life'. This refers to thinkers whose ideas 'reach across cross disciplinary boundaries and into popular culture' (Stanley and Wise 2000, 272). Stanley and Wise observe that these figures are perceived as 'in effect transcending their “social locatedness" as a person' and as a consequence their theoretical production is understood as being 'characterized by its generality and therefore its ability to be applied to other "similar" contexts and situations' (272). In the process they also tend to 'transcend' the discipline they emerged from to become known as 'philosophers', whether or not philosophy is prepared to own them.

I want to emphasise that I am not arguing against crossing disciplinarily boundaries. All else aside it would be bizarre of me to do so while quoting Stanley and Wise who are situated within the social sciences and posing some 'awkward questions' about the 'missing revolution' in feminist theory. Indeed, reading Stanley and Wise's article I am reminded how illuminating the correspondences in debates around the relationship between theory and practice in theatre and performance studies and in feminism can be for thinking about both areas, once the differences between them are acknowledged and taken into account.

Equally, I am not questioning that knowledge production of any kind embraces the particular and the general, the material and the abstract and that these do not necessarily 
function as 'oppositions', or as mutually exclusive but ideally, exist side by side, in to borrow from Laura Cull's brilliant essay 'Performance as Philosophy: Responding to the Problem of “Application”, a 'mutually transformative encounter' (2012, 23).

Barltrop's thesis strongly supports Cull's position in this essay, in which she argues for the need to reconceive what 'counts as philosophy' (21). However, as this statement implies in the academy, not all theories, theorists (or indeed disciplines) are considered equal, and with a very small number of notable exceptions, overwhelmingly the ideas which are presumed to transcend locatedness and be generalisable (still, after all these years) tend to be (dare I say it) overwhelmingly to be produced by straight, white, European men. The same applies to what I have called 'canonical practitioner-theorists', by which I refer to experienced and established practitioners whose ideas about theatre and performance (usually expressed in writing) achieves the status of 'theory' (but seldom, I note, 'philosophy'), meaning their ideas are perceived as generalisable (at least within the field), rather than relevant only to their own genre of practice, or that of a small group of similarly socially located 'others'. (Please also read this statement in reverse).

As the sort of person who reads articles about feminist theory I was bound to say this, although I know some people might find it irritating, not least because it doesn't offer any 'new knowledge'. Just as well I am not trying to make a proper argument.

\section{What is a proper argument?}

Stanley and Wise also discuss the relationship between theory, power and the concept of an argument, or rather, the 'ethical and political ramifications of conventional ideas about argument', in a manner that has some resonance with Cull's description of the problem of the 'application' of philosophy to performance. Cull discusses this in terms of 'the subordination of the powers of one practice or process to the needs and goals of another, the instrumentalization (sic) of the example for the purposes of an argument which has little 
interest in the example itself beyond its value for that argument' $(2014,21)$. What is interesting about this comment is it that it might be interpreted to suggest that what is of value in this sort of approach is neither the 'example' nor necessarily the philosphy but rather the argument.

I think it is the demand for a particular form of argument as a signifier of value and of 'new knowledge' that encourages the sort of 'application' approach Cull critiques, not least because this usually entails 'applying' theories already recognised as 'legitimate'. Equally, this demand can engender 'oppositional' postures for their own sake and/or generalised statements that make large, abstract claims for the import and the impact of the 'examples' (and/or the field as a whole) that can be very hard to substantiate outside of the argument itself. All of this may lend seriousness and legitimacy to the subject area but it suggests a defensive position, a lack of confidence in theatre and performance on its own terms, which are sometimes illegitimate, low, comic and frivolous.

Ironically, of course, some of the most celebrated 'travelling theorists' (and canonical practitioner -theorists) either ignore and/or transform the conventions of the 'proper' scholarly argument and such innovations can be crucial to the production of 'new knowledge'. Nevertheless, for these innovations to be perceived as 'legitimate', the writer has to have some recognised authority in the first place, which can be 'earned' by experience but too often is a matter of social and institutional locatedness.

\section{References}

Barltrop, Zoe. 2011. The Erotics of Circus: Boundaries, Transgression and Excess in Contemporary Circus Performance. Lancaster University. 
Borgdorff, Henk. 2006 'The debate on research in the arts'. Amsterdam School of the Arts. http://www.ips.gu.se/digitalAssets/1322/1322713_the_debate_on_research_in_the_arts.pdf. Accessed July 10, 2015.

Cull, Laura. 2012. 'Performance as philosophy: responding to the problem of "application".'

Theatre Research International, 37 (1): 20-27. doi:10.1017/S0307883311000733

Hann, Rachel, and Ladron de Guevara, Victor. 2015. 'Addressing practice:

introducing a new section for STP.' Studies in Theatre and Performance, 35 (1): 3-6. doi: $10.1080 / 14682761.2015 .1006833$

Piccini, Angela. 2003. 'An historiographic perspective on practice as research.' Studies in Theatre and Performance, 23(3): 191-207.

Stanley, Liz, and Wise, Sue. 2000. 'But the empress has no clothes! Some awkward questions about the "missing revolution" in feminist theory.' Feminist Theory, 1(3): 261-288. doi:10.1177/146470010000100301.

Welton, Martin. 2003. 'Against inclusivity: a happy heresy about theory and practice.' New Theatre Quarterly, 19 (4): 347-351. doi:10.1017/S0266464X0300023X

\footnotetext{
${ }^{\mathrm{i}}$ I decided not to name this person because she has not finished her $\mathrm{PhD}$, because while working with her has 'inspired' some of the questions raised in this piece they are not specific to her topic and because my comments reflect my own views, which she may or may not share.

ii On the question of 'low theory', I would suggest the large amount of cutting edge, intelligent and provocative material published on the internet calls for a re-think of what qualifies as 'theory' and who qualifies as a 'theorist'.
} 